\title{
Karotid arter darlığında 3D-TOF MR ve kontrastlı MR Anjiografi ile DSA bulgularının karşılaştırılması
}

Comparison of carotid artery stenosis 3D-TOF MR and contrast-enhanced MR Angiography with DSA findings

Çiğdem Öztürk Turan ${ }^{1}$, Ender Uysal ${ }^{2}$

1. Radyoloji Kliniği, Uşak Üniversitesi Tıp Fakültesi Eğitim ve Araştırma Hastanesi, Uşak/Türkiye

2. Radyoloji Kliniği, İstanbul Hamidiye Etfal Eğitim ve Araştırma Hastanesi, İstanbul/Türkiye

\section{ÖzeT}

AMAÇ: Günümüzde gelişmiş ülkelerde inme, sık morbidite ve 3. en sık mortalite nedenidir. Karotid arter darlığı, geçici iskemik atak ve inmenin önemli bir nedenidir. Kateter anjiyografi, karotid arterlerinin incelenmesinde altın standart olarak kabul edilir. Manyetik Rezonans Anjiyografi(MRA) ise; radyasyon içermemesi, kontrastsı ya da düşük doz kontrast madde ile yapılabilmesi ve incelemenin birçok kez tekrar edilebilmesi nedeniyle, karotid arter darlığının saptanmasında non invaziv etkin bir görüntüleme yöntemi olarak sıklıkla kullanılmaktadır. Bu çalışmada karotid arter darlığının MRA ile değerlendirilmesi, sonuçlarının DSA ile karşılaştırılması ve 3D TOF MRA ve Kontrastlı MRA'nın bu konudaki tanısal değerinin araştırılması amaçlanmıştır.

GEREÇ VE YÖNTEM: Bu çalışmada, Eylül 2009 ile Mart 2010 tarihleri arasında, GiA ve inme öyküsü, baş dönmesi, dengesizlik, hemipleji gibi sebeplerle başvuran 21 hastanın ana, internal ve eksternal karotid arterleri 3D TOF MRA, Kontrastlı MRA ve DSA ile görüntülendi.

BULGULAR: 3D TOF MRA, Kontrastlı MRA ve DSA ile değerlendirilen 21 hastanın( 42 arter), darlık düzeyleri, NASCET kriterlerine göre iki kez değerlendirilip, hesaplandı. Darlıklar hafif, orta ve ileri dereceli olmak üzere evrelendirildi. 3D TOF MRA ve Kontrastlı MRA sonuçları DSA bulguları ile karşılaştırıldı. Iki yöntemin bulguları da DSA ile uyumlu bulundu.

SONUÇ: Bu çalışmada 3D TOF MRA ve Kontrastlı MRA'nın, karotid arter darlığı tanısında DSA' ya alternatif olabilecek non invaziv bir inceleme olduğu sonucuna varıldı.

Anahtar Kelimeler: Karotid arter, stenoz, MR Anjiyografi, DSA

\section{ABSTRACT}

OBJECTIVE: Today, in developed countries, stroke, frequent morbidity and 3 is the most common cause of mortality. Carotid artery stenosis, transient ischemic attack and stroke is an important cause. Catheter angiography for the evaluation of carotid artery is considered the gold standard. Magnetic Resonance Angiography (MRA) of the radiation does not contain a contrast-free or lowdose contrast material and can be made and the investigation of the many times repeated be due to carotid artery stenosis in determining non-invasive effective imaging as a method often used. This study of carotid artery stenosis with MRA evaluation of the results of 3D TOF MRA and DSA comparison and contrast with MRA 's this issue was to investigate the diagnostic value.

MATERIALS AND METHODS: In this study, in September 2009 and March 2010, between TIA and stroke, dizziness, ataxia, hemiplegia, which can differ in clinics admitted 21 patients in the main, internal and external carotid arteries, 3D TOF MRA, the contrast MRA and DSA and displayed.

RESULTS: 3D TOF MRA, the contrast can be evaluated with MRA and DSA of 21 patients (42 arteries), shortness of levels, both times have been evaluated according to NASCET criteria, respectively. Stenosis as mild, moderate and advanced stages were to be rated. 3D TOF MRA and contrast MRA results were compared with DSA findings. The findings of the two methods were consistent with the DSA.

CONCLUSION: In this study, 3D TOF MRA and contrast-enhanced MRA's, the DSA in the diagnosis of carotid artery stenosis alternatives that may be concluded that a noninvasive examination

Key Words: Carotid artery, stenosis, MR Angiography, DSA

Yazışma Adresi/Address for Correspondence: Çiğdem Öztürk Turan, MD, Radyoloji Kliniği, Uşak Üniversitesi Tıp Fakültesi Eğitim ve Araştırma Hastanesi,

Uşak/Türkiye

E-Posta/E-Mail: drcigdemozturk@hotmail.com || Tel:

Received/Geliş Tarihi: 16 Tem 2018 || Accepted/Kabul Tarihi: 25 Tem 2018

Bu Eser Creative Commons Atıf-Gayriticari 4.0 Uluslararası Lisansı İle Lisanslanmıştır. This work is licensed under a Creative Commons

Attribution-NonCommercial 4.0 International License (CC BY-NC 4.0). 


\section{GiRiş}

Günümüzde gelişmiş ülkelerde inme, sık morbidite ve 3. en sık mortalite nedenidir (1). Karotid arter darlığı, Geçici İskemik Atak (GIA) ve inmenin önemli bir nedenidir. Erişkindeki kranioserebral vasküler darlıkların en sık nedeni ise aterosklerozdur. Aterosklerozun görülme sıklığı yaşla birlikte artar ve inme gelişme olasılığı damardaki darlık derecesi ile yakından ilişkilidir.

Kateter anjiyografi, karotid arterlerin incelenmesinde altın standart tanı yöntemi olarak kabul edilir. Ancak, yöntemin invaziv ve pahalı olması ultrasonografi (US), manyetik rezonans görüntüleme (MRG) ve bilgisayarlı tomografi (BT) gibi invaziv olmayan ya da minimum invaziv olan görüntüleme tekniklerinin daha da geliştirilmesine yol açmıştır. MR Anjiyografi (MRA) karotid arterlerin değerlendirilmesinde sık olarak başvurulan invaziv olmayan bir görüntüleme yöntemidir. İki ve üç boyutlu görüntülerin kontrast madde verilmeden ve iyonizan ışına maruz kalmadan elde edilebilmesi, aynı zamanda yumuşak dokuların da aynı incelemede değerlendirilebilmesi yöntemin önemli avantajlarındandır. Bu çalışmada karotid arter darlığının MRA ile değerlendirilmesi, sonuçlarının DSA ile karşılaştırıması ve MRA'nın bu konudaki tanısal değerinin araştırılması amaçlanmıştır.

\section{GEREÇ VE YÖNTEM}

Bu çalışmada, Eylül 2009 ile Mart 2010 tarihleri arasında, GiA ve inme öyküsü, baş dönmesi, dengesizlik, hemipleji gibi sebeplerle kliniğimize refere edilen hastaların ana, internal ve eksternal karotid arterleri 3D TOF ve kontrastlı MRA ile görüntülendi. MRA ' da karotid arterlerde darlık saptanan ya da internal serebral arterlerde darlık şüphesi olan 21 hasta DSA için dış merkezli bir Radyoloji Kliniğine sevk edildi.

Tüm olgular klostrofobi, kardiyak pacemaker, kardiyoverter, defibrilatör, MRG uyumluluğu bulunmayan cerrahi klip ve protez açısından tarandı; bunlardan birisi veya daha fazlasına mevcut olan olgular çalışma dışı bırakıldı.

Tüm hastalar 1,5 T MR cihazı (Philips İntera Achieva; Philips Medical Systems, Nederland) ile değerlendirildi. Hastalar supin pozisyonda, çok kanallı yüksek dansiteli bir beyinboyun koili boyunlarına yerleştirilerek çekime hazırlandı. MRA için rutin 3D TOF, SPGR yöntemiyle, 23/6.91 ms $(\mathrm{TR} / \mathrm{TE})$, flip angle( FA $)=20^{\circ}, \mathrm{NEX}=1, \mathrm{FOV}=210$, Matrix $=$ $368 \times 512$ ve kesit kalınlığı $1.6 \mathrm{~mm}$ olacak şekilde elde edilen kesitlerden; transvers düzlemde komprese reformat MRA görüntüleri incelendi. Elde edilen görüntüleme bilgisi, Philips iş istasyonuna (workstation) aktarıldı. Burada elde edilen ham görüntülerde incelenen kesitlerden, Maksimum intensite projeksiyonu (MIP) tekniği kullanılarak koronal planda MultiPlanar Volüm Rekonstrüksiyon (MPVR) görüntüler elde edildi. Arka plandaki dokudan gelen sinyali azaltmak ve böylece arka plan ve akan kan arasındaki kontrast farkını artırmak için Manyetizasyon Transferi yöntemi kullanıldı.

Kontrastlı MRA için TR ve TE minimum değerde tutularak, $\mathrm{FA}=30^{\circ}, \mathrm{NEX}=1, \mathrm{FOV}=400$, Matrix $=288 \times 320$ ve kesit kalınlığı $1 \mathrm{~mm}$ olacak şekilde elde edilen kesitlerden MIP tekniği ile koronal planda MPVR görüntüler elde edildi. Hastalara ortalama 20-30 cc Gd- DTPA manüel olarak enjekte edildi. Ortalama toplam MRA inceleme süresi 10-15 dakikaydı.

MRA ve DSA tetkikleri arasındaki süre 1 hafta ile 1 ay arasında değişmekte olup ortalama 10 gündü.

DSA Axiom Artis FA ( Siemens, Germany ) Monoplan cihazı ile gerçekleştirildi. İncelemeye ana femoral artere $5 \mathrm{~F}$ introduser yerleştirilerek başlandı. Öncelikle arterlerin çıkımındaki olası anatomik ve patolojik değişikliklerin görüntülenmesi amacıyla arkus aortagrafi yapıldı. Her iki CCA, AP / Lateral; gerekli olgularda oblik olarak görüntüler elde edildi. Her bir görüntüde $8 \mathrm{ml}$ non-iyonik kontrast madde kullanıldı. Arkus aortagrafi, selektif karotid, vertebral arter ve serebral anjiyografi çekimleri yapıldı. İşlem bitiminde komplikasyon gelişmemesi için 15-20 dk. kompresyon uygulandı. Olguların hiçbirinde komplikasyon gelişmedi.

Her olgu için tanıya yönelik optimal görüntü seçilerek; DSA, 3D TOF MRA ve kontrastlı MRA görüntüleri incelendikten sonra, darlık derecesi, Kuzey Amerika semptomatik karotid endarterektomisi çalışması [North American Symptomatic Carotid Endarterectomy Trial (NASCET)] kriterleri göz önüne alınarak ve damar çapı submilimetrik olarak ölçülerek her biri için ayrı ayrı hesaplandı (2). Karotid arterdeki en dar segmentin aksiyel uzunluğu ile stenoz distalinde normal kalibrasyondaki karotid arterin aksiyel uzunluğu oranlanarak hesaplandı. Hesaplamalar yapılırken stenoz distalinde izlenen poststenotik dilate segment dikkate 
alınmayarak dilatasyonun normale döndüğü lokalizasyondan ölçümler yapıldı. (Şekil 1).

\section{Darlıkların sınıflandırılmasında altı derece kullanıldı:}

- I: Normal

- II: Hafif dereceli darlık ( \% 1 -29)

- III: Orta dereceli darlık ( \% 30-50)

- IV: Orta dereceli darlık ( \% 50-69)

- V: Illeri dereceli darlık(70-99)

- VI: Oklüzyon

şekil 1. NASCET, ECST ve CC yöntemlerine göre karotis stenoz ölçümü.

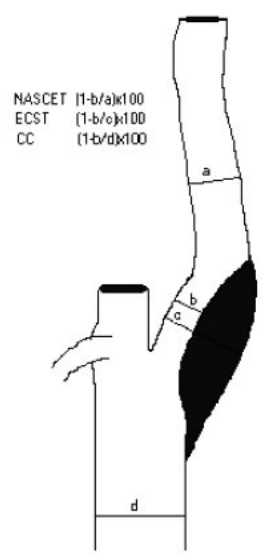

Bu çalışmada ekstrakraniyal karotid arterler DSA, 3D TOF ve kontrastlı MRA ile değerlendirildi. Bu görüntüleme yöntemleri ile darlığın derecesi analiz edildi. MRA ve DSA bulguları karşılaştıılarak, MRA'nın bu konudaki tanısal değeri araştırıldı.

İstatistiksel analizde DSA altın standart olarak kabul edildi. 3D TOF MRA, kontrastlı MRA ve DSA'nın darlık kategorileri ile ilgili sonuçları arasındaki korelasyon NCSS 2007 paket programı kullanılarak ağırlıklı kappa testi ile belirlendi.

\section{BULGULAR}

Bu çalışmaya 21 hasta dahil edilmiş olup hastaların 5'i kadın 16'sı erkekti. Kadın hastalar 57-90 (ortalama 75+15.362) yaşlar arasında iken erkek hastalar 46-82 (ortalama $68.9+10.711)$ yaşlar arasında idi. Çalışmamızdaki olgular evre II, III, IV, V ve VI stenozdan oluşuyordu. Toplamda 42 karotid arter incelenmiş olup bunlardan 31 tanesinde karotid arterde darlık saptandı. DSA ve MRA incelemelerinin hiçbirinde işlem sırasında ya da sonrasında komplikasyon gelişmedi.

3D TOF MRA ve Kontrastlı MRA ile DSA sonuçları arasında anlamlı korelasyon saptandı. ( 3D TOF MRA: $\mathrm{Kw}=0.956, \mathrm{P}=$ 0.0001; Kontrastlı MRA: $\mathrm{KW}=0.824, \mathrm{P}=0.0001$ ) (Tablo 1 ve 2).
DSA ve 3D TOF MRA sonuçlarının duyarlılık 0,955, özgüllük 0,833, PKD 0,933, NKD 0,882, testin doğruluğu 0,919, LR(+) değeri 5,727 bulundu. DSA ile hasta dediğimiz kişinin 3D TOF MRA sonucunda da hasta olma olasılığı 5,72 kat daha fazla saptandı.

Tablo 1. Sağ IKA' da saptanan darlıkların 3D TOF, Kontrastlı MRA ve DSA ile karşılaştırılması.

\begin{tabular}{|llcccc|}
\hline \multicolumn{1}{|c|}{ Olgu } & Yaş & Cinsiyet & 3D TOF & K.MRA & DSA \\
1. FS & 46 & E & III & III & III \\
2. MB & 72 & E & VI & VI & VI \\
3. MI & 68 & E & IV & III & III \\
4. AD & 57 & K & IV & IV & IV \\
5. LÇ & 76 & E & V & V & V \\
6. OK & 73 & E & IV & IV & IV \\
7. MT & 62 & K & VI & VI & VI \\
8. MD & 66 & E & IV & IV & V \\
9. IE & 72 & E & VI & VI & VI \\
10. PK & 57 & E & III & III & III \\
11. AA & 81 & E & III & III & III \\
12. KÖ & 67 & E & III & III & III \\
13. IY & 79 & E & IV & IV & IV \\
14. ZÖ & 50 & E & III & III & III \\
15. HK & 90 & K & IV & IV & IV \\
16. EB & 77 & E & IV & IV & IV \\
17. HY & 61 & E & IV & IV & IV \\
18. IFT & 76 & E & V & V & V \\
19. AY & 82 & E & V & V & V \\
\hline
\end{tabular}

Tablo 2. Sol IKA' da saptanan darlıkların 3D TOF, Kontrastlı MRA ve DSA ile karşılaştırılması.

\begin{tabular}{|lccccc|}
\hline Olgu & Yaş & Cinsiyet & 3D TOF & K.MRA & DSA \\
1. MB & 72 & E & V & V & V \\
2. MI & 68 & E & IV & IV & III \\
3. LÇ & 76 & E & III & III & III \\
4. MD & 66 & E & V & V & V \\
5. PK & 57 & E & III & III & III \\
6. AA & 81 & E & V & V & V \\
7. KÖ & 67 & $\mathrm{E}$ & $\mathrm{V}$ & $\mathrm{V}$ & $\mathrm{V}$ \\
8. ZÖ & 50 & $\mathrm{E}$ & $\mathrm{II}$ & $\mathrm{II}$ & $\mathrm{II}$ \\
9. HK & 90 & $\mathrm{~K}$ & $\mathrm{~V}$ & $\mathrm{~V}$ & $\mathrm{~V}$ \\
10. EB & 77 & $\mathrm{E}$ & $\mathrm{V}$ & $\mathrm{V}$ & $\mathrm{V}$ \\
11. MS & 66 & $\mathrm{E}$ & $\mathrm{V}$ & $\mathrm{V}$ & $\mathrm{V}$ \\
12. GN & 76 & $\mathrm{~K}$ & $\mathrm{VI}$ & $\mathrm{VI}$ & $\mathrm{VI}$ \\
\hline
\end{tabular}

DSA ve Kontrastlı MRA sonuçları ağırlıklı kappa ile değerlendirilmiş olup ağırlıklı kappa değeri $\mathrm{Kw}=0,824$, $p=0,0001$ bulundu. DSA ve kontrastlı MRA sonuçları istatistiksel olarak anlamlı derecede uyumlu bulundu.

DSA ve Kontrastlı MRA sonuçlarının duyarlılık 0,955, özgüllük 0,889, PKD 0,955, NKD 0,889, testin doğruluğu 0,935, LR(+) değeri 8,591 saptandı. DSA ile hasta dediğimiz kişinin Kontrastlı MRA sonucunda da hasta olma olasılığı 8.59 kat daha fazla saptandı.

Evre II Hafif dereceli darlık (\%1-29): 3D TOF MRA, Kontrastlı MRA ve DSA 1 olguda \%100 uyumlu olarak bulundu.

Evre III Orta dereceli darlık (\%30-50): 3D TOF MRA ile 7 olguda DSA ile uyumlu bulundu (\%78). Kontrastlı MRA ile 8 
olguda uyumlu bulundu (\%89). DSA ile bilateral iKA'da evre III darlık saptanan, geçici iskemik atak nedeniyle başvuran olgu 3'de, 3D TOF MRA ve kontrastlı MRA' da evre IV darlık olarak değerlendirildi.

Darlıkları evrelerine göre sınıflandırdığımızda (Grafik 1,2 ve 3)

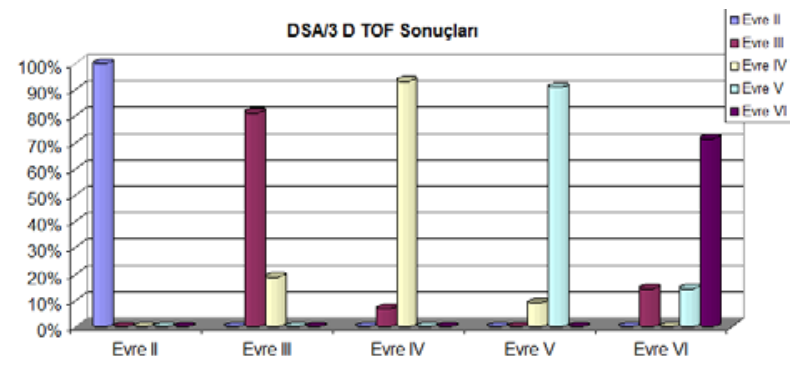

Grafik 1

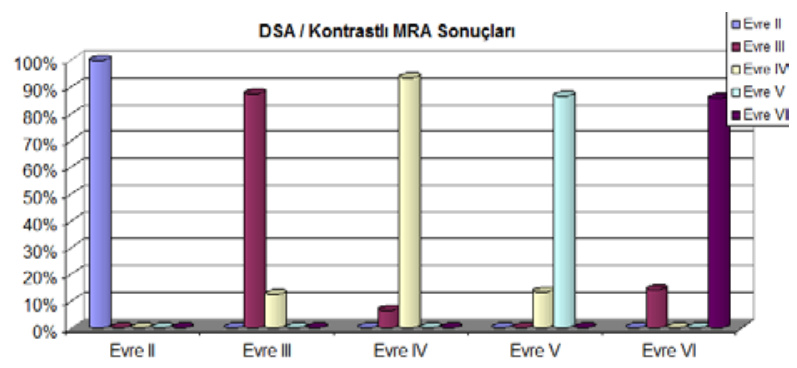

Grafik 2

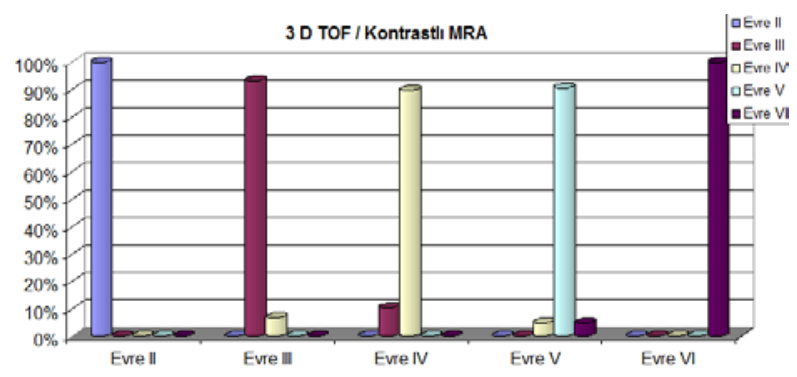

Grafik 3

Evre IV Orta dereceli darlık (\%50-69): 6 olgunun 3D TOF MRA ve kontrastlı MRA bulguları DSA ile uyumlu bulundu (\%75). DSA ile evre III olarak değerlendirilen olgu 3'ün bilateral IKA'da 3D TOF MRA ve kontrastlı MRA ile evre IV darlık olarak değerlendirildi. 3D TOF MRA ve Kontrastlı MRA ile evre IV olarak değerlendirilen olgu 8'de DSA sonucu evre $\checkmark$ darlık ile uyumlu bulundu.

Evre V ileri dereceli darlık (\%70-99): DSA ile 10 IKA' da evre V ileri dereceli darlık saptandı ve tamamı 3D TOF MRA ve kontrastlı MRA ile görüntülenerek \%100 uyumlu bulundu. Evre VI oklüzyon: DSA ile 4 IKA' da oklüzyon mevcuttu. 3D TOF MRA ve Kontrastlı MRA ile 4 olgunun tümünde (\%100) oklüzyon gösterildi.

\section{Olgu Örneği:}

73 yaşında semptomatik erkek hastada, sağ iCA proksimalinde evre IV darlık saptandı (Resim 1).

\section{Resim 1.}
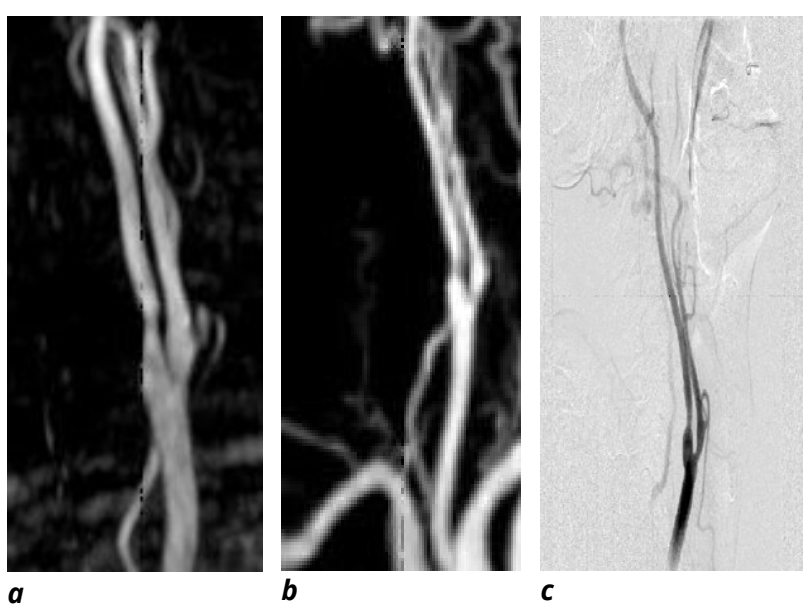

Sağ ICA da ,3D TOF MRA(a), Kontrastlı MRA(b) ve DSA(c)' da evre IV darlık.

\section{TARTIŞMA}

NASCET ve Avrupa Karotid Cerrahisi Çalışması [Europian Carotid Surgery Trial (ECST)] ileri dereceli (\% 70-99) ve semptomatik karotid arter darlığı olan hastaların, medikal tedavi ile kıyaslandığında, endarterektomiden ve stent uygulanmasından önemli oranda yarar gördüğünü rapor etmektedir $(3,4)$. Masaryk'e göre, endarterektomiden fayda görebilecek hastaların belirlenmesinde görüntüleme yöntemlerinden beklenen, darlığı doğru olarak derecelendirmesi, ileri darlığı oklüzyondan ayırt etmesi ve eşlik eden tandem lezyonları saptamasıdır. Bunlara ek olarak, kullanılan modalite hastaya en az düzeyde risk ve maliyet getirmelidir (5).

Malek ve arkadaşları (6) yüksek riskli semptomatik hastalarda servikal karotid arter stenozu için anjiyoplasti ve/veya stentleme ile ilgili çalışmalar yapmışlardır. Bunlar NASCET kriterlerine göre cerrahi olarak dışlanan hastaları çalışmaya dahil etmişlerdir. Bir hastada majör inme (\%3.6), 3 hastada geçici iskemik atak (\%10.7) meydana gelmiştir. İşleme bağlı ölüm görülmemiştir.

Kateter anjiyografi karotid arter darlıklarının değerlendirilmesinde altın standart tanı yöntemi olarak kabul edilmektedir. Bunun nedeni uzun zamandan beri kullanılagelen bir tanı yöntemi olması ya da anatomik doğruluğu değildir. Kateter anjiyografi cerrahi girişimden 
sağlanan klinik fayda ile spesifik olarak korelasyon gösteren tek tanı yöntemidir. Diğer bir avantajı, hem ekstrakraniyal hem de intrakraniyal karotid arteriyel sisteminin tek seansta incelenmesine olanak sağlaması, cerrahi stratejiyi etkileyebilecek karotid sifon darlığı veya kollateral dolaşım hakkında bilgi vermesidir. Ayrıca kateter anjiyografi plak düzensizliklerini, cerrahi risk ve hastanın prognozu açısından önemli olabilecek mural trombüs ya da ülserasyonları saptayarak, damar duvarının yüzey anatomisi hakkında da bilgi edinilmesini sağlayabilir (7).

Kateter anjiyografi önemli avantajlara sahip bir modalite olmasının yanında, invaziv bir girişimdir. Waugh ve arkadaşlarının (8) DSA ile 2475 hasta üzerinde yapmış oldukları prospektif çalışmada, lokal komplikasyon oranı \% 7.3, sistemik komplikasyon oranı \% 1.8 olarak rapor edilmiştir. Aynı çalışmada karotid ve serebral anjiyografisi yapılan 939 hastada geçici nörolojik defisit oranı \% 0.6, kalıcı nörolojik defisit oranı ise \% 0.3' tür. DSA ile 1095 hasta üzerinde yapılan bir başka prospektif çalışmada, geçici nörolojik defisit oranı $\%$ 0.45, kalıcı nörolojik defisit oranı $\%$ 0.09 olarak bildirilmiştir. Aynı çalışmada geçici iskemik atak ve inme öyküsü nedeni ile anjiyografisi yapılan hastalarda ise kalıcı nörolojik defisit oranı \% 0.3' tür (9).

Nörolojik komplikasyon oranı çok çok düşük bile olsa, sonuçta DSA invaziv bir modalitedir ve basit bir laboratuvar testi değildir. Ayrıca maliyeti de oldukça yüksektir. Bu nedenle karotid arterlerinin incelenmesinde daha ucuz, invaziv olmayan ya da minimum düzeyde invaziv olan görüntüleme tekniklerine ihtiyaç duyulmuştur.

Doppler US diğer modalitelere göre daha ucuz, kolay tolere edilebilen ve gerektiğinde durumu ciddi olan hastaları yataklarında incelemek amacıyla cihazı taşınabilen bir tanı yöntemidir. Patel ve arkadaşlarının (10) NASCET kriterlerini göz önüne alarak yapmış oldukları bir çalışmada, ileri dereceli darlıkların tanısında Doppler US'nin duyarlıı̆̆ı \% 94, özgünlüğü \% 83, doğruluğu ise \% 86 olarak bildirilmiştir. Daha eski yayınlarda duyarlılık \% 91-94, özgünlük ise \% 8599 olarak rapor edilmiştir (11).

Doppler US' nin önemli bir dezavantajı, total oklüzyonu subtotal oklüzyondan ayırt etmede her zaman yeterli olmayışıdır. Darlık oklüzyona doğru yaklaştıkça, akım hızı pek çok Doppler sistemiyle saptamanın mümkün olmadığı 2 cm/sn'nin altına düşer. Doppler US ile total oklüzyon tanısı konan arterlerin \% 5 i le \% 15'inde anjiyografi ile ileri dereceli darlık saptandığı bildirilmiştir (12). Böyle darlıklar renkli Dopplerin yavaş akıma duyarlı ayarları ile tam oklüzyondan ayrılabilir. Power Dopplerde görüntüyü oluşturan Doppler kayması değil Doppler sinyalinin gücüdür ve subtotal oklüzyonu oklüzyondan ayırabilir. Ayrıca eko arttırıcı kontrast maddeler oklüzyon tanısının doğrulanmasına ya da operasyon şansı yaratan ince rezidüel lümenin saptanmasına yardımcı olabilir (13).

BTA' de aksiyel kesitlerle, uygun pencere genişliği ve düzeyi sağlandığı takdirde, mural kalsifikasyon ve kontrast madde ayrımı kolaylıkla yapılabilmekte, MiP ve SSD imajlarında lümeni çevreleyerek değerlendirmeyi imkansız kılan kalsifikasyonların varlığında bile rezidüel lümen rahatlıkla seçilebilmektedir.

Konvansiyonel anjiyografi vasküler yapıların görüntülenmesi amacıyla kullanılan altın standart bir yöntemdir. Ancak arteriyel kateterizasyon, uygulanan kontrast madde, iyonize radyasyon gibi dezavantajları vardır. Son yıllarda sık kullanılmaya başlanan BTA da DSA'da olduğu gibi iyonizan radyasyon içermesi, kontrast madde kullanılması ve operatöre bağımlı olması gibi dezavantajlara sahiptir. MRA, son yıllarda vasküler yapıları değerlendirmede kullanılan non invaziv, güvenli bir görüntüleme modalitesidir.

Son yıllarda, iv kontrast madde kullanılarak ve TE süresi çok kısa tutularak gerçekleştirilen üç boyutlu MRA, konvansiyonel MRA'daki, temporal rezolüsyonun yeterli olmaması, yavaş ya da kompleks akımdan kaynaklanan, darlık derecesinin ve dar segmentin uzunluğunun olduğundan fazla görünmesi gibi sınırlamaları ortadan kaldıran bir yöntem olarak uygulanmaya başlanmıştır. Gadolinyum kanın T1 zamanını kısaltarak TOF tekniğindeki akıma bağlı kontrastlanmayı daha da arttırır. Sinyal oluşumu nispeten akımdan bağımsız bir hale geldiğinden, kan protonlarının durağan dokulara benzer şekilde satüre olma problemi neredeyse tamamen ortadan kalkar. Böylece TR, konvansiyonel TOF' a göre çok daha kısa tutulabilir. Bunun sonucunda, zemin baskılaması daha etkili olur ve veri kazanımı çok daha kısa sürede yapılır. Kan akım hızının çok yavaşladığı totale yakın oklüzyonlarda, konvansiyonel TOF ile, satürasyon etkisine bağlı olarak yanlışlıkla tam oklüzyon tanısı konabilir. Ancak kontrast kullanıldığı takdirde bu durum ortadan kalkar ve rezidüel lümen çok 
büyük bir doğrulukla gösterilebilir. Ayrıca, bulbusta kompleks akımdan kaynaklanan sinyal kaybı, kontrastlı MRA' da görülmez ve türbülan akıma bağlı olarak abartılı olabilen darlık dereceleri daha doğru olarak saptanabilir $(14,15)$.

MRA ileri dereceli karotid darlığının saptanmasında duyarlılı̆ı yüksek olan bir tanı yöntemidir. 2D TOF MRA, darlık derecelerini 3D TOF MRA' ya göre daha fazla abartma eğilimindedir. 2D ve 3D TOF MRA tekniğinin birlikte kullanımı, darlık derecelerinin belirlenmesinde MRA'nın özgünlüğünü arttırabilir $(16,17)$.

Literatürde karotid arter oklüzyonu tanısında MRA için \% 100 doğruluk bildiren yayınların yanında, ileri derece darlığa oklüzyon ve oklüzyona, ileri derece darlık tanısının konulduğu çalışmalar da vardır. Bizim çalışmamızda da, bir olgunun sağ iCA proksimalindeki darlık, 3D TOF MRA ile evre IV olarak değerlendirilirken kontrastlı MRA ve DSA' da evre III ile uyumlu bulunmuştur. Aynı hastanın sol iCA çıkımında 3D TOF MRA ve kontrastlı MRA' da evre IV olarak değerlendirilen darlık, DSA' da evre III ile uyumlu olarak hesaplanmıştır. Yine bu çalışmadaki diğer bir olguda da sağ iCA proksimalinde 3D TOF MRA ve kontrastlı MRA'da evre IV olarak değerlendirilen darlık, DSA' da evre $\vee$ darlık ile uyumlu bulunmuştur. Yavaş akıma daha duyarlı olduğu için 2D TOF MRA'nın, 3D TOF MRA ile birlikte kullanımı ya da kaynak kesitlerin incelenmesi bu tip hataları önleyebilir (18).

Darlık derecelendirmesinde NASCET kriterleri kullanılarak yapılan bu çalışmamızda; 3D TOF MRA'nın duyarlılı̆ı \%95, özgüllüğü \%83, pozitif prediktif değeri \%93, negatif prediktif değeri \%88 ve doğruluğu \%92 olarak saptanmıştır. Kontrastlı MRA'nın ise duyarlılığı \%95, özgüllüğü \%89, pozitif prediktif değeri \%95, negatif prediktif değeri \%89 ve doğruluğu \%93 olarak hesaplanmıştır. Çalışmada ulaşılan bu oranlar, karotid arter darlığı ve oklüzyonu tanısında 3D TOF MRA ve kontrastlı MRA'nın DSA'ya alternatif noninvaziv bir görüntüleme yöntemi olarak düşünülebileceğini göstermiştir. 3D TOF MRA ve kontrastlı MRA bulguları DSA bulguları ile istatistiksel olarak anlamlı bulunmuştur.

\section{DSA, 3D TOF MRA ve Kontrastı MRA istatistiksel sonuçları}

\begin{tabular}{|ccc|}
\hline & Kw & $p$ \\
DSA & 0.912 & 0.0001 \\
3D TOF MRA & 0.910 & 0.0001 \\
Kontrastlı MRA & 0.956 & 0.0001 \\
\hline
\end{tabular}

3D TOF MRA ve kontrastlı MRA'nın duyarlılı̆ı her ikisinde de eşit olup, \%95 olarak bulunmuştur. 3D TOF MRA ve kontrastlı MRA'nın özgüllükleri sırasıyla \%83 ve \%89; doğrulukları ise $\% 92$ ve $\% 93$ olarak bulunmuş olup kontrastlı MRA'nın özgüllüğü ve doğruluğu 3D TOF MRA'ya göre biraz daha fazladır. Ancak her iki tetkikinde duyarlılı̆ı, özgüllüğü ve doğruluğu oldukça yüksek olarak bulunmuş olup DSA ile istatiksel olarak anlamlı oldukları saptanmıştır.

DSA işleminin invaziv olması, nefrotoksik kontrast madde verilmesi, iyonizan radyasyon içermesi gibi çeşitli dezavantajları göz önünde bulundurulursa, MRA'nın her iki türünün de DSA'ya alternatif olabileceği bu çalışmanın sonuçları doğrultusunda söylenebilir. 3D TOF MRA ve kontrastlı MRA kendi aralarında karşılaştırılacak olursa, kontrastlı MRA ile çok az bir fark olmasına rağmen, bu çalışmada 3D TOF MRA'ya göre daha doğru sonuçlar vermiştir. Ancak 3D TOF MRA'nın da kontrastlı MRA kadar DSA'ya alternatif olabileceği bu çalışmayla söylenebilir. Bu çalışma sonucunda, son yıllarda MR kontrast maddelerle oluşabilecek Nefrojenik Sistemik Fibrozis (NSF) riski düşünülürse; kontrast madde kullanımının sakıncalı olduğu hasta grubunda 3D TOF MRA'nın DSA'ya alternatif olarak, hastaya kontrast madde verilmeden uygulanabileceğini söyleyebiliriz.

\section{SONUÇ:}

$\mathrm{Bu}$ çalışmada karotid arter darlıklarının derecelendirilmesinde, MRA ile en güvenilir sonuçların kontrastlı MRA ile elde edildiği, 3D TOF MRA'nın da yüksek duyarlılığa ve özgüllüğe sahip olup, kontrast madde verilmesinin sakıncalı olduğu hasta grubunda DSA'ya alternatif olarak kullanılabilecek non invaziv bir yöntem olduğu görülmüştür. Bu konuda yapılmış olan çalışmalarla büyük ölçüde uyumlu sonuçlar elde edilmiştir.

Yazarlar arasında çıkar çatışması yoktur.

The author declares no conflict of interest.

Finansal Destek: yoktur / Funding : none

doi: ${ }^{* * * * * * * * * * * * * *}$

\section{KAYNAKLAR}

1. Beuchamp NJ, Brayn RN. Acute cerebral ischemic infarction: Apathophysiologic review and radiologic perspective. AJR 1988; 71: $73-83$.

2. North American Symptomatic Carotid Endarterectomy Trial 
Collaborators. Beneficil effect of carotid endarterectomy in symptomatic patients with high grade stenosis. Eng J Med 1991; 325: 445-453.

3. Europian Carotid Surgery Trialists Collaborative Group. MRC Europian carotid surgery trial: iriterim results for symptomatic patients with severe $(\% 70-99$. or with mild $(\% 0-29$. carotid stenosis. Lancet 1991; 337: 1235-1243.

4. Moore WS. Fundamental considerations in cerebrovascular disease. p. 1713- 1730. In Rutherford RB (ed): Vascular Surgery, ed 5. Philadelphia, WB Saunders, 2000.

5. Masaryk TJ, Obuchowski NA. Noninvasive carotid imaging: Caveat Emptor. Radiology 1993; 186: 325-331.

6. Malek A, Higashida RT, Phatouros CC et al. Stent angioplasty for cervical carotid artery stenosis in high-risk symptomatic NASCET-ineligible patients. Stroke 2000; 31: 3029-3033.

7. Wolpert SM, Caplan LR. Curent role of cerebral angiogragraphy in the diagnosis of cerebrovascular diseases. AJR $1992 ; 159: 191-197$.

8. Waugh JR, Sacharias N. Arteriographic complications in the DSA era. Radiology 1992; 182: 243-246.

9. Gryzyska U, Freitag J, Zeumer H. Selective cerebral intraarterial DSA.Complication rate and control of risk factors. Neuroradiology 1990; 32(4): 296-299.

10. Patel MR, Klufas RA, et al. Preoperative assessment of carotid bifurcation. Magnetic resonance angiography and duplex ultrasonography replace contrast angiography. Stroke 1995; 26: 1753-1758.

11. Zwiebel WJ. Duplex sonography of the cerebral arteries: Efficacy, limitations, and indications. A JR.1992; 158: 29-36.

12. Erden I. Renkli doppler ultrasonografinin fizik prensipleri, sınırlamaları ve hata kaynakları. Türkiye Klinikleri Tıp Bilimleri 1991; 11: 326-351.

13. Staikov IN, Nedeltchev $K$, Arnold M, et al. Dupleks sonographic criteria for measuring carotid stenoses. J Clin Ultrasound 2002; 30: 275-281.

14. Alley MT, Shifrin RY, Pele NJ, Herfkens RJ. Ultrafast contrastenhanced threedimensional MR angiography : State of the art, Radiographics 1998; 18: 273-285.

15. Nederkoorn PJ, van der Graaf Y, Hunink MG. Duplex ultrasound and magnetic resonance angiography compared with digital subtraction angiography in carotid artery stenosis: a systematic review. Stroke 2003; 34(5): 1324-1332.

16. Deutsch LS. Anatomy and angiographic diagnosis of extracranial and intracranial vascular disease. In Rutherford RB (ed): Vascular Surgery, ed 5. Philadelphia, WB Saunders, 2000: 1744-1773.

17. Aschenbach R, Eger $C$, Basche $S$, et al. Grading of carotid artery stenosis using high resolution dynamic magnetic resonance angiography in comparison to intraarterial digital subtraction angiography. Are stenosis over $70 \%$ reliably detectable? Rofo. 2004; 176(3): 357-362.

18. Rozovsky MA, et al. Magnetic resonance angiography of the neck. Clinical implications. Neuroimaging Clinics of North
America 1996; 6(4): 863-873.. 